\title{
Boundary crossing pedagogy in STEM education
}

\author{
Allen Leung
}

\begin{abstract}
This commentary aims to discuss an overarching boundary crossing framework under which integrated STEM (Science, Technology, Engineering, Mathematics) pedagogy can be conceptualized. Four potential learning dialogical processes for boundary crossing are presented and used as the main theoretical construct for the discussion. A proposal of an interactive pedagogical framework is put forward accompanied by a provisional statement to relate the connective factors that are critical in the formation of a boundary crossing STEM pedagogy. These factors are situated learning, communities of practices, problem solving, learning dialogical processes, and boundary objects. A Hong Kong school STEM case is employed to illustrate the applicability of this framework. The commentary ends with a reflective remark on boundary crossing STEM pedagogy.
\end{abstract}

Keywords: STEM education, Integrated pedagogy, Boundary crossing, Boundary object, Learning dialogical processes

\section{Introduction}

A difficulty in conceptualizing STEM pedagogy is the epistemic obstacle encountered when one tries to cross from one STEM disciplinary knowledge domain to another. There are pedagogical content knowledge boundaries that need to be crossed as each STEM discipline has its own epistemic practices that cannot be changed easily. There is a

need for an overarching learning framework that elucidates the commonalities, the distinctions, and the relationships between the learning and practice of mathematics, science and engineering. (Burrows, Oehrtman, \& Lawson, 2006, p. 2)

STEM integration may occur at different levels (adopted from Vasquez, Sneider, \& Comer, 2013):

1. Disciplinary: concepts and skills are learned separately in each discipline

Correspondence: aylleung@hkbu.edu.hk

Department of Education Studies, Hong Kong Baptist University, Kowloon Tong Campus, Hong Kong, SAR, China
2. Multi-disciplinary: concepts and skills are learned separately in each discipline but within a common theme

3. Inter-disciplinary: closely linked concepts and skills are learned from two or more disciplines with the aim of deepening knowledge and skills

4. Trans-disciplinary: knowledge and skills learned from two or more disciplines are applied to realworld problems and projects, thus helping to shape the learning experience

One needs to be careful not to downplay the centrality of disciplinary knowledge. English (2016) advocated that if

we are to advance STEM integration and lift the profile of all of its disciplines, we need to focus on both core content knowledge and interdisciplinary processes.... strong STEM agendas have well-developed curricula that concentrate on twenty-first century skills including inquiry processes, problem-solving, critical thinking, creativity, and innovation as well as a strong focus on disciplinary knowledge. (p. 3)

This commentary aims to explore an overarching boundary crossing framework under which integrated
Springer Open

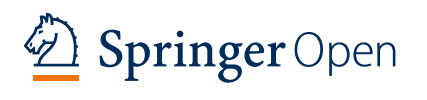

(c) The Author(s). 2020 Open Access This article is licensed under a Creative Commons Attribution 4.0 International License, which permits use, sharing, adaptation, distribution and reproduction in any medium or format, as long as you give appropriate credit to the original author(s) and the source, provide a link to the Creative Commons licence, and indicate if changes were made. The images or other third party material in this article are included in the article's Creative Commons licence, unless indicated otherwise in a credit line to the material. If material is not included in the article's Creative Commons licence and your intended use is not permitted by statutory regulation or exceeds the permitted use, you will need to obtain permission directly from the copyright holder. To view a copy of this licence, visit http://creativecommons.org/licenses/by/4.0/. 
STEM pedagogy can be conceptualized. The "Theoretical background" section presents the theoretical background of this proposal. The section "An interactive STEM pedagogy framework" states the content of a proposed interactive boundary crossing framework, and the section "An illustrative example" illustrates how this framework can be used as a lens to analyze a school STEM activity. The commentary ends with a reflective remark on boundary crossing STEM pedagogy.

\section{Theoretical background}

\section{Integrated STEM pedagogy}

Hallström and Schönborn (2019) conducted a comprehensive literature review to discuss that models and modeling could be used to foster an integrated and authentic STEM education. Here models refer to concrete visual artifacts that can represent conceptual ideas, for example, construction of prototype in engineering design. Models and modeling are important tools for problem solving, and it was proposed that models and modeling processes can bridge the gap between STEM disciplines through authentic practices.

Through processes of modelling in STEM education, the disciplines become bound by a synergistic relationship, often requiring a learner to transit between the learning areas while engaging scientific, mathematical and technological activities, which often render these processes interdependent (Hallström \& Schönborn, 2019, p. 2)

Leung (2019) explored a hybrid pedagogy that connects the STEM disciplines mathematics and science in the form of a pedagogical cycle where elements of mathematical modeling and inquiry-based learning are integrated. The purpose of this integration was to see how epistemic differences and similarities between the inquiry processes of two STEM disciplines could be coherently combined under one frame "without losing the disciplines' unique characteristics, depth, and rigor" (Corlu, Capraro, \& Capraro, 2014). The key inquirybased learning elements of posing and defining questions, developing, using a method of investigation, and interpreting results are present in these two disciplinary epistemic processes. In school science education, inquiry-based learning is a problem-based approach consisting five pedagogical phases (BSCS 5E Instructional Model): engagement, exploration, explanation, elaboration, and evaluation (Bybee et al., 2006). It was found that under specially designed pedagogical arrangement and approach, the integration of mathematical modeling and inquiry-based learning integration is possible. The case studied in Leung's work was a mathematics lesson sequence conducted in a secondary school's science laboratory. Students were asked to estimate the number of marbles contained in a large transparent flask without touching it. They were allowed to use different measuring instruments in the school's science laboratory to carry out their investigation. The teachers designed a problem-solving lesson sequence for students to follow. In the analysis, it was discovered that students' problemsolving work reflected the essence of inquiry-based learning and mathematical modeling. This suggests that when students solve STEM-related problems, it is possible to design a learning environment that could guide them to realize different STEM inquiry and modeling processes, and such a learning environment can encompass these processes. Thus, an idea of the need of an overarching framework to streamline STEM integration arises. In this connection, research work has been done to pedagogically combine the scientific inquiry process and application of mathematics via purposeful design and inquiry (Sanders, 2009) and Inquiry in Mathematics Education (Artigue \& Baptist, 2012).

Kelly and Knowles (2016) presented an integrated STEM education conceptual framework metaphorically by a block and tackle of four pulleys (the four STEM disciplines) lifting a load (situated STEM learning). The pulley system is driven by a Community of Practice wherein participants (e.g., teachers and students) co-learn STEM skills and the thinking and inquiry of different STEM practices. A Community of Practice is based on a social learning theory and is defined as "groups of people who share a concern, a set of problems, a passion about a topic and who deepen their knowledge and expertise in that area by interacting on an ongoing basis" (Wenger, McDermott, \& Snyder, 2002, p. 4). Kelly and Knowles' framework sees STEM education as the setting up of a pulley system designed to efficiently lift the cognitive load of a contextual situation. STEM education is a situated learning consisting of the four STEM "pulleys" arranged and customized to tackle the given contextual situation. A Community of Practice pulls the rope to activate this epistemic system. In this sense, STEM pedagogy can be organized as a pedagogical system in which different STEM components interact with each other under the dynamism generated by participants of a Community of Practice. Aside from considering the integration of the STEM discipline domains, studying the dynamic interaction among the STEM disciplines and social domains should be a fruitful direction to develop STEM pedagogy. How to cross the boundary between knowledge domains and Communities of Practice becomes a relevant research question. The following discussion will pursue this direction.

\section{Communities of Practice}

The concept of Communities of Practice is rooted in an aim to develop accounts of the social nature of human learning. Three crucial elements distinguish a Community 
of Practice from other social groups: domain, community, and practice. That is, it is a group of people with a shared domain of interest who engage together in different types of social activities to pursue this shared interest, consequently forming a community of practitioners to develop a shared collection of resources. A key idea in Communities of Practice is that learning is seen as the production of social structure. Meaning making in a social context involves the dual process of participation and reification (making into an object). Engaging in different types of social activity and production of concrete artifacts go hand in hand to form iterative cycles of learning. The history of this iterative process becomes an informal and dynamic social structure among the participants (Wenger, 1998, 2015).

The teaching and learning of a school subject discipline can be regarded as a Community of Practice whose core members are the subject's teachers and students. Participation and reification are the daily activities inside and outside the classrooms. An overarching STEM pedagogy deals with more than one Community of Practice (Science, Technology, Engineering, Mathematics), thus forming a bigger Community of Practice, and some members of these communities have multiple memberships. A major task to develop a dynamic STEM pedagogy is to study how the Communities of Practice interact with and cross each other's boundary.

\section{Boundary crossing}

Learning as production of practices creates knowledge boundaries. A key concept to address the complexity of the integrated STEM pedagogy phenomenon is boundary crossing among different knowledge domains. Mediating objects are needed to bridge the disciplines' pedagogical content knowledge gaps. Instead of seeing a boundary as an obstacle, it should be viewed as a potential for learning since a boundary contains common concerns on both sides.

A boundary can be seen as a sociocultural difference leading to discontinuity in action or interaction. Boundaries simultaneously suggest a sameness and continuity in the sense that within discontinuity two or more sites are relevant to one another in a particular way. (Akkerman \& Bakker, 2011, p. 133)

When diversity is embraced, the challenge is to create possible boundary objects that can cross the boundary between different domains and serve to negotiate, combine, and translate from different contexts to achieve hybrid situations (Engeström, Engeström, \& Kärkkäinen, 1995). Boundary objects, defined by Star and Griesemer (1989), are

objects which are both plastic enough to adapt to local needs and the constraints of several parties employing them, yet robust enough to maintain a common identity across sites. They are weakly structured in common use, and become strongly structured in individual-site use. These objects may be abstract or concrete. They have different meanings in different social worlds but their structure is common enough to more than one world to make them recognizable, a means of translation. The creation and management of boundary objects is a key process in developing and maintaining coherence across intersecting social worlds (Star \& Griesemer, 1989, p. 393).

Boundary objects articulate meaning and address multiple perspectives. They allow "different groups to work together based on a back-and-forth movement between ill-structured use in cross-site work and well-structured use in local work" (Akkerman \& Bakker, 2011, p. 141). Boundaries and boundary objects are ambiguous in nature. It is this uncertainty that creates a space for learning at the boundary, which can entertain multiple meanings for a phenomenon.

Dillion (2008) developed generic ideas of pedagogy of connection and boundary crossings between disciplines which take account of interventions, the use of tools, and the notion of changes in learning behavior. Akkerman and Bakker (2011) in their literature review on boundary crossing saw boundaries as dialogical phenomena and identified four potential learning dialogical processes that can take place at the boundaries: identification, coordination, reflection, and transformation. In summary (see ibid. pp. 142-150 for a full explication):

Identification is about defining one practice in light of another, delineating how it differs from the other practice, thus establishing legitimate coexistence of different practices.

Coordination involves (i) a communicative connection between diverse practices that can be achieved via boundary objects, (ii) efforts of translation between different worlds, (iii) increasing boundary permeability, and (iv) establishing cross boundary operational routines.

Reflection is about realizing and explicating differences between practices and thus to learn something new about their own and others' practices and formulating distinctive perspectives (perspective making). It creates a possibility to look at oneself through the eyes of other worlds. These processes enrich one's identity beyond its current status (perspective taking).

Transformation involves (i) confrontation between different practices, (ii) recognition of a shared problem space with the boundary object as a mediating object, (iii) hybridization where a new and unfamiliar cultural form emerges combining ingredients from different 
practices, and (iv) crystallization where something hybrid is embedded into practice so that it has real consequence. It takes place by means of developing new routines or procedures that embody what has been created or learned, maintaining (v) uniqueness of the intersecting practices, and (vi) continuous joint work at the boundary and the process of meaning negotiation, thus preserving the productivity of the boundary crossing.

These four dialogical processes characterizing boundary crossing can be a feasible model to frame pedagogy in STEM education as STEM is heterogeneously involving different pedagogical content knowledge boundaries. As mentioned in the previous section, Leung (2019) explored STEM pedagogy in the mathematics classroom by proposing a hybrid boundary object that connected the STEM disciplines mathematics and science. It took the form of an inquiry-based modeling pedagogical cycle in which elements of mathematical modeling and scientific inquirybased learning were combined. The cycle is regarded as a boundary object that can be used as a lens to organize boundary crossing pedagogical activities between science and mathematics. Leung's study analyzed a STEM lesson under this lens and consequently identified a few STEM boundary pedagogy features: contingent classroom interactions, room for mistakes, development of tool-based task design and tool-based reasoning discourse, applicability and extension, refinement, and modification (ibid.). These features can be re-interpreted under the four dialogical processes. To extend the inquiry-based modeling pedagogical cycle for science and mathematics, a generic problem-solving cycle may serve as a boundary object for all STEM disciplines.

\section{Problem solving in STEM}

Problem solving plays a central role in STEM education. STEM learning and thinking is usually situated in the context of problem solving (see, for example, Li et al., 2019; Priemer et al., 2019). A view for STEM boundary crossing is to regard the problem-solving process as a boundary object. Different STEM disciplines have their own problem-solving process (which are inquiry-based learning, computational thinking, engineering design, and mathematical modeling, respectively). Investigating the commonalities and differences of the STEM disciplines' problem-solving heuristics could be a key to integration. Leung (2018) compared and contrasted the STEM disciplines' problem-solving processes and subsumed them under a universal frame modeled after Pólya's problem-solving cycle (Pólya, 1945). An overarching problem-solving process (a boundary object) can be regarded as a kind of "STEM language" or a compatible epistemological approach to translate or transfer pedagogies between the STEM disciplines. A major difficulty in STEM integration is that teachers from different
STEM disciplines, understandably, usually have difficulty communicating with each other. Having a common STEM language (e.g., a commonly accepted overarching problem-solving strategy) acting as a boundary object may alleviate teachers' academic tension between the STEM disciplines.

\section{STEM literacy and thinking}

In a recent research on STEM literacy (i.e., a set of capabilities that a STEM literate person should possess), Tang and Williams (2019) examined the literacies across the STEM disciplines to identify similarities and differences in order to determine whether there is a collective conceptualization of these literacies. A distinction between STEM literacy and S.T.E.M. literacies (individual disciplinary literacies) was proposed. It was suggested that there should be an interweaving continuum between the two. Furthermore,

the boundaries between the development of these literacies is permeable, and all individuals are at different points on the spectrum as they develop towards being literate. (Tang \& Williams, 2019, p. 692-693)

Hence, an implicit idea of boundary crossing in terms of common literacy skills across the STEM disciplines emerged.

More research in identifying common literacy skills across the STEM disciplines will further strengthen and substantiate the validity of STEM literacy as an educational construct. (Tang \& Williams, 2019, p. 693)

With respect to STEM literacy skills, in an editorial on thinking and STEM education (Li et al., 2019), thinking was viewed as cognitive processes and strategies in problem-solving activities. Thinking in integrated STEM education was suggested to be reconceptualized and differentiated into multiple models, instead of the traditional concept of thinking as a single process consisting of different components.

Individual models can be identified and developed as pertinent to thinking that takes place either in individuals or in groups. Each model can also refer to discipline-general or discipline-based thinking that have been the focus of previous studies such as mathematical reasoning, computational thinking, design thinking, and critical thinking. (Li et al., 2019, p. 9)

\section{An interactive STEM pedagogy framework}

In the above discussions on STEM integration, the concept of an interweaving framework between multiplicity and commonality in problem-solving context begins to 
take shape. Building on the author's work in exploring a problem-based integrated hybrid pedagogy for science and mathematics (Leung, 2019), an interactive STEM pedagogy framework is proposed in this section to further extend the boundary crossing idea to wider domains. The conceptualization of this framework was motived by a school's STEM project lesson that the author observed and discussed with the participating teachers. This STEM project lesson will be presented in the next section to illustrate and concretize the framework elements.

A STEM activity is often about asking students to solve a relevant authentic, usually ill-defined, problem in multiple creative ways. Collaboration across different domains is crucial. Participants (teachers and students) in a STEM class work together to shape the problem-solving processes. A framework for STEM pedagogy could take the form of a system structure where interrelated pedagogical components are interacting together via commonalities and boundary objects. Here boundary objects refer to those mediating artifacts that are conducive to bridging the pedagogical gaps among the STEM disciplinary domains. This pedagogical system should be fluid and ready to adapt to different shapes as the educational context changes. Figure 1 is a schematic representation of this framework. The four apexes are four major domains (can be more if necessary) in the pedagogical system that interact with each other in the process of boundary crossing via the agency of boundary objects. Learning dialogical processes identified by Akkerman and Bakker, problem solving, communities of practice, and boundary objects were discussed in the "Theoretical Background" section. Situated learning focuses on "the relationship between learning and social situations in which it occurs .... what kinds of social engagements provide the proper context for learning to take place" (Lava \& Wenger, 1991, p. 14). For STEM education, the social situation could be the pedagogical environment that the students are engaging in, for example, a school laboratory, a digital classroom, a field trip to a museum, and a robotic competition.

Accompanying this interactive pedagogical framework is the following provisional statement for STEM pedagogy:

STEM pedagogy is about situated contextual teaching and learning where participants from educational Communities of Practice (e.g. teachers, students) socially co-construct solutions and knowledge for addressing relevant real-world problems through boundary crossing dialogical and problemsolving processes that involve more than one STEM discipline.

This statement captures the essential concepts presented in Fig. 1 and could be a generic approach for cross-disciplinary pedagogy; that is, other knowledge domains can join the system. It expands into details when applied to specific enactment of STEM education in a school. In this sense, this STEM pedagogy would ultimately serve as a boundary object for different pedagogical domains. A major undertaking to study this framework is to investigate the interactions among the apexes through boundary crossing and to find out the boundary objects needed to do the crossing. The purpose of setting up this interactive framework is an attempt to

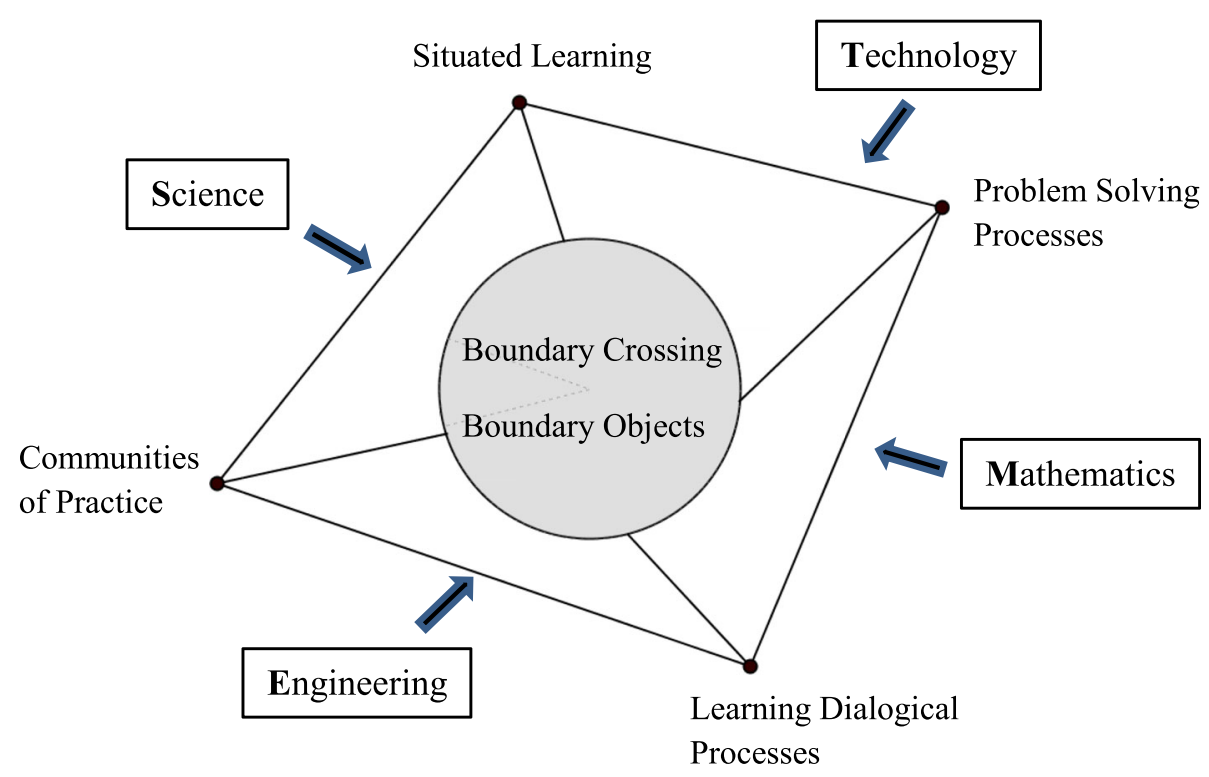

Fig. 1 An interactive framework for STEM pedagogy 
create an overarching map to conceptualize and operationalize integrated STEM education.

In the following section, an example of a STEMrelated lesson from a Hong Kong secondary schools (shared by the school's teachers) is described and discussed. This example was the inspiration to motivate the formation of the provisional statement and the interactive pedagogical framework. Therefore, the analysis presented in the next section illustrates the ideas suggested in the framework with a concrete example.

\section{An illustrative example}

The case example described in this section was from a secondary school in Hong Kong. To understand the recent STEM education situation in Hong Kong and the larger educational environment behind this school case, a brief introduction of Hong Kong STEM education is sketched below.

STEM education was first announced in the Hong Kong 2015 Government Policy Address. The government's Education Bureau (EDB) has been very proactive in promoting this mandate in the primary and secondary school sectors. The Report on Promotion of STEM Education: Unleashing Potential in Innovation (Education Bureau of Government of HKSAR, 2016) called for holistic strategies to nurture school students' creativity, collaboration, innovation, and problem-solving skills in Science, Technology, and Mathematics. Studentcentered pedagogies are encouraged to facilitate integrative problem-solving skills, learning to code, and entrepreneurial spirit. Suggestions on STEM education strategies to enrich quality learning experiences for students have mostly been exercised through extracurricular activities focusing on competitions, exhibitions, collaboration with STEM-related organization, and school-based STEM-related activities. However, there are neither concrete directions nor common consensus on how to approach STEM education in the Hong Kong context. Educational activities that have an ICT (Information Communication Technology) component, mainly coding, would be labeled as STEM activity. Science, Engineering, and especially Mathematics are usually under the shadow of coding and robotics.

A few schools have been implementing crossdisciplinary classroom teaching in Science, Mathematics, and ICT before 2015 (like the school case presented in this section). This was usually initiated and led by passionate teachers who have strong subject matter knowledge and who have broad visions to cross their own subject boundaries. The interpretation of STEM education has expanded rapidly into diversified forms and, in particular, other subject domains like Art are being incorporated into the STEM movement, hence the popularization of STEAM education. In this connection,
Hong Kong STEM education is moving gradually towards a cross-disciplinary direction. The currently discussed STEM literacy concept in the more developed STEM education systems, such as Australia and USA (see for example Tang \& Williams, 2019), is still in a very novice stage in the Hong Kong context. One purpose of presenting a school case in this section is to illustrate an example of STEM-related lesson design that Hong Kong teachers engage in. STEM-related means the pedagogical activities in the lesson design cover a broad range of knowledge domains that include some, if not all, STEM disciplines and other knowledge disciplines. In the case presented below, geography was included. Motivated by this school case, the proposed interactive framework for STEM pedagogy (Fig. 1) took its form. The framework is generic enough to allow other knowledge domains to join in and hence possibly extending it to a STEM Plus pedagogy (at least two STEM disciplines plus one other non-STEM subject discipline).

\section{Background of the STEM project}

Secondary school $\mathrm{M}$ began cross-disciplinary activities involving Mathematics, Science, and ICT since 2013 before the Hong Kong STEM education initiative mandated in 2015. The school has an ICT Team consisting mostly of higher form students who participate on a voluntary basis. The Team is led by an able and experienced teacher (Ms. A) who is the head of the school's ICT Department and who is passionate with organizing and overseeing STEM activities for students. In 2015, Ms. A led the students from the ICT Team to accept an invitation to participate in an international science exhibition in Belgium. They visited the Royal Belgian Institute of Natural Sciences which is one of the largest dinosaur-themed museums in the world. During the museum visit, the students came across an interactive activity where they had to act like a paleontologist to excavate dinosaur bones in a makeshift sand pit using authentic archeologist brush. In the activity, students learned about the relationship between the size of a type of fossil bone (thigh bone) and the weight of the dinosaur. The students initiated an idea that they would like to replicate this activity in their school and Ms. A was delighted to support this teaching and learning project.

\section{The STEM activity}

Ms. A's usual practice is to let students design the STEM lesson/activity that they initiated by themselves with support and advice from her and other teachers. The ICT Team students (in Form 4 and Form 5, i.e., Grade 10 and Grade 11 equivalent) decided that the STEM lesson was for Form 3 (Grade 9) students and they titled it "A Day as a Paleontologist." The ICT Team students designed and constructed makeshift sand pits 
and modelled the dinosaur fossil bones using plaster with reference to pictures found on the Internet. Figure 2 is one of those makeshift sand pits after brushing.

Having this model artifact in place, the ICT Team students, using advices from different subject teachers, designed a sequence of 10 activity tasks, with worksheets, for Form 3 classes. This design of sequenced activities was motivated by the teachers and students' past experience of collaborative STEM task design. The task sequence was an attempt to enact a simplified exploration practice of a paleontologist. The work of a paleontologist involves subject knowledge beyond STEM; hence, this activity was actually a STEM Plus activity. The Form 3 class students were divided into groups. They were provided with different sand pits, regarded as sites, like the one in Fig. 2. The first activity task was to grid the site with strings and to draw a sketch-map of it. Afterward students used a brush properly to remove the sand on the fossil bones and to identify the thigh bone. The thigh bone was used to estimate the dinosaur weight (Fig. 3).

To perform the weight estimation, it was necessary to know the circumference of the thigh bone's cross section. Since the fossil bones were not supposed to be taken out of the site, mathematical modeling was needed to estimate the circumference. A reasonable assumption was that the cross section of the bones takes an elliptical shape (Fig. 4).

The ICT Team students found a Ramanujan's formula for elliptical circumference $(p)$ from the Internet:

$$
p \approx \pi(a+b)\left(1+\frac{3 \mathrm{~h}}{10+\sqrt{4-3 \mathrm{~h}}}\right) \text { whereh }=\frac{(\mathrm{a}-\mathrm{b})^{2}}{(\mathrm{a}+\mathrm{b})^{2}}
$$

This formula was a new mathematical knowledge for the students and for the teachers, but they had no doubt about its validity because of Ramanujan's fame. An iPad App was found that could measure the major axis of the

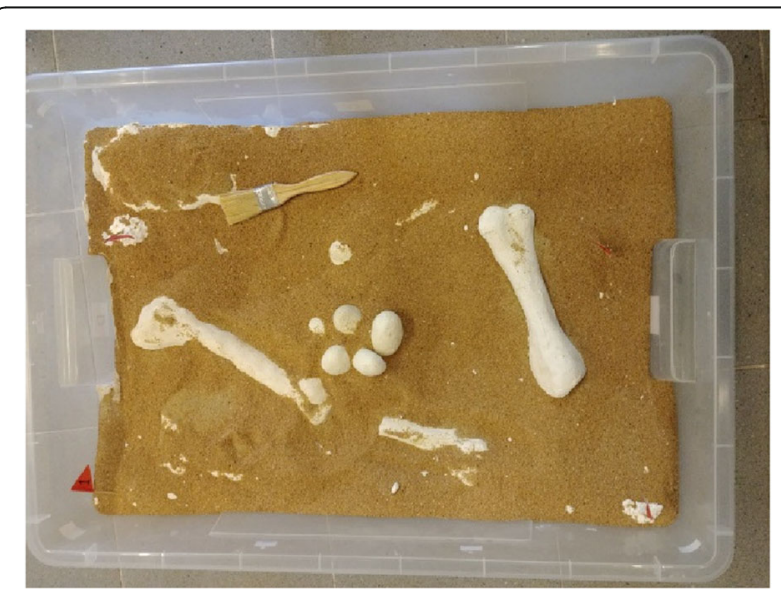

Fig. 2 A student-constructed archeological sand pit with fossil bones fossil bone's cross section. To estimate the minor axis, one could assume that the fossil bone cross section is like the one depicted in Fig. 4 and use a similarity argument to calculate the desired answer for the semi-minor axis of the makeshift bones.

Finally, students were asked to obtain a circumference-weight chart like the one in Fig. 5a from the Internet to extrapolate a circumferenceweight graph (Fig. 5b) and use this graph to estimate the weight of the dinosaur. The lesson ended with the ICT teacher asking the students to write a pseudo-code for the Ramanujan's formula for elliptical circumference.

The following is a summary of the 10 activity tasks.

\section{Geography}

Task 1: Draw a sketch-map.

Task 2: Short question: Do you think the dinosaur died at where you found the fossil? Why?

\section{Biology}

Task 3: Shade the thighbone: a dinosaur skeleton and two dinosaur head bones drawings were shown.

Task 4: Short question: What is the type of dinosaur, carnivore, or herbivore shown in the above skeleton? Give a reason for your answer.

\section{Mathematics supported by ICT tool}

Task 5: Find the weight of the dinosaur

5.1: Find the length of the semi-major axis of the cross section

5.2: Find the length of the semi-minor axis of the cross section

Task 6: Plot a graph to find the mass of the dinosaur Task 7: Long question:

Is the formula for estimating the circumference of an ellipse valid? By considering the case where the lengths of the major and the minor axes are equal, verify the validity of the formula. [Hint: What figure will you get if the length of the major and the minor axes are equal?]

Task 8: Long question:

Someone suggests that the method used is not accurate in estimating the weight of the dinosaur. List THREE possible sources of errors.

ICT

Task 9: Write the pseudo-code of the ellipse formula.

Task 10: Short question: Suggest ONE advantage of writing programs to find the circumference.

\section{Reflection with respect to the interactive framework} This STEM Plus lesson involved four subject disciplines: Geography, Biology, Mathematics, and ICT. 


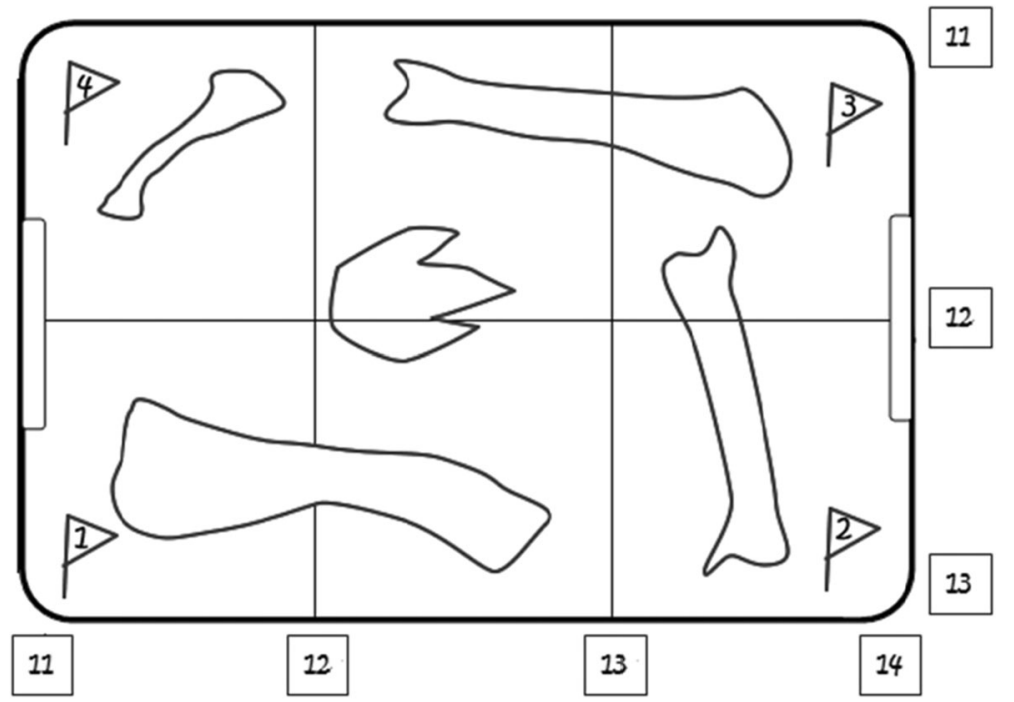

Fig. 3 A sketch-map of a map with the fossil bones revealed

\section{Situated contextual teaching and learning}

The lesson was motivated by an out-of-classroom experience in a world-class scientific museum. It mimics the work of paleontologists who are scientists in possession of diverse subject knowledge to solve complex archeological problems. This is the kind of lesson that meets the purpose and aim of STEM education: preparing our students for a STEM-related career (in this case, learning from being a paleontologist) for the advancement of human knowledge and betterment of our society.

\section{Communities of practice}

It was a student-initiated and student-designed project lesson, and the teachers from the relevant subject disciplines collaborated to ensure success. Different subject teachers played supportive advisory roles to co-construct the pedagogical task sequence with the students. Therefore, Communities of Practice (of students and of teachers) were formed and they interacted with each other. STEM lesson is not only for students, an important stakeholder is the teachers. The readiness and openness of the teachers are deterministic factors for the success of a STEM lesson. School M has an ICT Team headed by teacher Ms. A who has a vision to promote cross-subject teaching and learning activities. She believes that students should know how to apply knowledge in integrative ways and know that different subjects are interrelated. The school has an IT room for the ICT Team where workshops for students can be held to construct and design materials for STEM activities. It is interesting to note that even though Ms. A is an ICT expert teacher, there are no digital artifacts in the IT room. She prefers concrete raw materials that students can handle and play with in designing STEM activities. Furthermore, the school principal who believes STEM education is for every student, not just the smart ones, provides pivotal support to establish a STEM school culture. He believes that students have different learning processes and individual differences and that the school curriculum

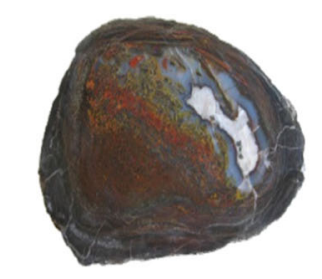

Utah \& Colorado Dino Leg Bone

http://petrifiedwoodmuseum.org/JurassicAnimalGallery5.htm

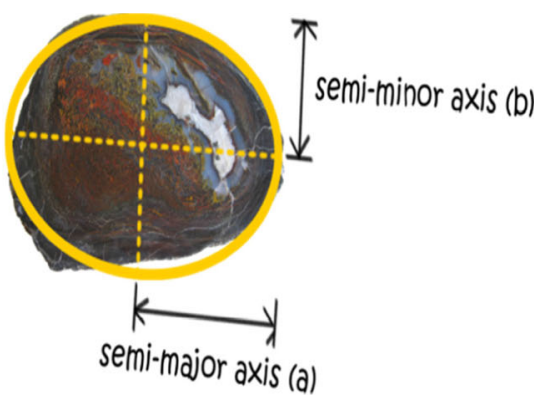

semi-major axis (a)

Fig. 4 Leg bone information obtained from the Internet and geometrical modeling used to estimate the circumference 


\begin{tabular}{|c|c|}
\hline Circumference (cm) & Weight (kg) \\
\hline 5 & 7 \\
\hline 10 & 46 \\
\hline 15 & 140 \\
\hline 20 & 306 \\
\hline 25 & 563 \\
\hline 30 & 926 \\
\hline
\end{tabular}

(a)

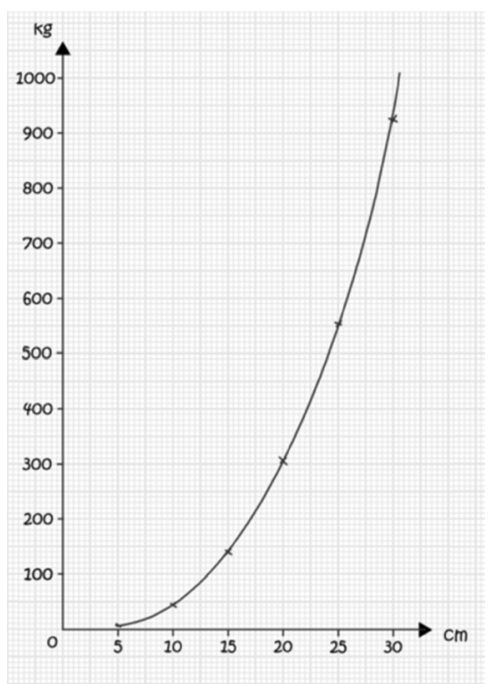

(b)

Fig. 5 a A circumference-weight chart. b An extrapolated circumference-weight graph

should be adjusted to allow cross-subject explorative lessons that are coherent across subjects. Consequently, the whole school becomes a STEM Community of Practice.

\section{Knowledge co-construction and real-world problem solving}

School $M$ is actively promoting a practical scientific investigation culture. When students design STEM activities, apart from engaging in different subject matters, they are encouraged to design the activities for participating students to develop hands-on and problemsolving skills using simple materials. Teachers and students co-construct "STEM knowledge" to address contextual problems. The student-designed lesson pushed the participating teachers out of their subject comfort zone and became STEM learners themselves. The Geography teacher learned about sketching plane sketch-map for an actual 3-dimensional physical site, an activity that is not in the school Geography curriculum. For the Mathematics teacher, the Ramanujan's formula for elliptical circumference was new to him. Students found the formula on the Internet and spent a lot of time discussing it with the Mathematics teacher. Outside classroom knowledge makes connection with curriculum knowledge and how such knowledge can be used in the real world. Students enjoyed the lesson and gained new perspectives in their learning. Mathematics plays a central role in the lesson. Students realized the usefulness of mathematics as a "real" science and experienced that a step-by-step problem-solving process could link mathematics to other subjects.

The whole lesson design had mathematics threaded through the tasks. Drawing the sketch-map for the pit needs knowledge on scaling which involves measurement unit, similarity, and proportional reasoning. Finding the circumference of the bone needs mathematical modeling, measurement technique, geometrical reasoning, similarity, proportional reasoning, approximation, and to know how to make decision on what formula to use and how to use it. Estimating the weight of the dinosaur reveals the need to find authentic data source in order to extrapolate a graph for the estimation. Finally, errors in the estimation are discussed. Hence, overall, underlying this STEM lesson was learning how to use mathematical knowledge to conduct a scientific investigation to solve an archeological problem; a kind of hybridization between mathematical modeling and the scientific inquiry process (see Leung, 2019).

\section{Boundary crossing, boundary object, and dialogical processes}

An exceptional characteristic of this STEM Plus lesson is that the lesson was initiated, designed, and prepared by students with support from relevant subject teachers. School $\mathrm{M}$ uses this pedagogical approach to conduct STEM education. This student-centered model is the driving force for School M's boundary crossing pedagogical approach. Akkerman and Bakker's (2011) four learning dialogical processes in boundary crossing play out quite naturally in this case.

Identification STEM education involves different subject disciplines, each having its own pedagogical practice. The identity of each subject in institutionalized school curriculum is distinct and robust. In the case presented, the lesson involved Geography, Biology, Mathematics, and ICT. 
Coordination The makeshift sand pit containing fossil bones (the site) constructed by the students can be regarded as a boundary object as it became the common communicative object that connected the focus of attention of the four subject disciplines. Geography focused on sketch-map, Biology on the types of bones, Mathematics on modeling, and ICT on the use of digital app and pseudocoding. All these are connected through the site as the dialogical piece.

The step-by-step task sequence designed by the students can be regarded as a common text for the boundary object. It acted as an explanation of (in a sense translating) the context and the objectives of the lesson. The task sequence was straight forward and was a kind of operational routine for the students and the subject teachers to carry out. The straightforward transition from one task to another task eases the pedagogic tension between the subjects and thus increased the boundary permeability.

Reflection Teachers and students realized how one subject discipline can be relevant to another subject discipline with respect to a common context. A paleontologist could at the same time be a practicing geographer, a biologist, a mathematician, and an IT expert. The lesson allowed both the teachers and the students to see the possibility of looking at themselves through the eyes of different disciplines and thus expanded their knowledge domains. The students indicated that they had an experience of looking at their own mathematics-selves through the eyes of other subject disciplines. This is an enrichment of one's knowledge identity beyond one's current status.

Transformation The usual confrontation between different subject teachers was alleviated since the lesson was initiated by a student team. Students did most of the planning, design, and construction, and they consulted different subject teachers for advice. In this way, the subject teachers shared a problem space with the students using the sand pit as a mediating boundary object. This lesson project is an example of a non-traditional school culture in which students and teachers became collaborators in a pedagogical process. It can be regarded as student-teacher hybridization of different pedagogical practices. The boundary between student and teacher has become very flexible and permeable.

School M has been creating new cross-disciplinary lessons like this one, all designed by the ICT Team student, in the past few years and is continuing to do so. Old lessons have been modified and are re-taught when appropriate circumstances arise. Consequently, each involved discipline is strengthening its unique identity at the boundary as each plays a deterministic role in the lessons, while at the same time joining other disciplines in a constant negotiation of new integrated knowledge. This is a crystallization process.
School M has motivated the key interacting components of the interactive framework (Fig. 1) and exemplified the description of the provisional statement for STEM education. It is a foundational example upon which the type of STEM pedagogy proposed can be further developed.

\section{Concluding remarks}

In Leung (2019), the author aimed to "explore and search for boundary pedagogy that acts as communicator between the epistemological and pedagogical approaches in the mathematics and science classrooms" (p. 1355). An inquiry modeling cycle was proposed to build a boundary object connecting two knowledge acquisition domains, and this inquiry modeling cycle is a local realization of the interactive framework for the STEM pedagogy presented in Fig. 1. Hence, the interactive framework is a global overarching extension of the ideas discussed in Leung (2019).

From the school case discussed above, one can see that STEM pedagogy is a complex pedagogical phenomenon. It involves checks and balances between domains and communities that are locally situated. The main difficulty is to find or construct appropriate boundary objects to transfer knowledge across sites. Hence, in a sense, a STEM pedagogy should also possess the characteristics of a boundary object, that is, it is plastic enough to adapt to local needs and constraints and robust enough to maintain a commonly shared structure. The interactive framework depicted in Fig. 1 and the accompanying provisional statement about STEM (Plus) pedagogy were intended to express this thought. There needs not be a fixed definition of what STEM education is; rather, there should be overarching principles to guide the development of STEM education in different social and educational contexts. The interactive framework presented in this commentary is a step forward in this direction. It uses boundary crossing as the main overarching idea to alleviate the tensions and to regulate the communication among different STEM (and beyond) domains.

Boundary is a place where ambiguity rules, but ambiguity has the potential to open new interpretations and practices. Different epistemic ways to cross the STEM disciplinary boundaries determine the types of pedagogical approach to be employed, for example, interdisciplinary, multi-disciplinary, trans-disciplinary, or even meta-disciplinary. Such epistemic decisions are made according to many factors that cannot be globally standardized. Different school and cultural practices mold different STEM education realizations. However, a key common factor is collaboration among teachers across the STEM subjects. STEM education is not targeted for student learning only, it should also be a 
boundary platform where teachers from different school subjects come together to learn and to expand and enrich their pedagogical context knowledge.

This commentary discusses integrated STEM pedagogy and boundary crossing between STEM Communities of Practice. An interactive framework accompanied by a provisional statement is proposed to map out the connective factors that are critical in forming STEM pedagogy. This serves as an overarching frame to guide the operation of STEM applications in situated sites. The Hong Kong school case presented in this commentary motivated and ascertained the applicability of this framework. The question is how different STEM practices can be measured by this overarching frame. Disciplines other than STEM can enter the interactive frame, and when that happens, more epistemic nodes are expected to be added for the expansion of the framework. Under this framework, a research direction would be to investigate the construction and utilization of specific mechanisms (e.g., boundary objects) for boundary crossing which can consequently create a pedagogical environment where the STEM, and other, disciplines can work harmoniously together for the participants to construct the needed knowledge and skills, hence contributing to STEM literacy. This is an ideal goal that hopefully can be realized in the future. The complexity of how to interpret STEM education by different stakeholders is not easy to regulate, especially for the emergence of viable STEM pedagogies that could reach this goal. Nevertheless, the discussion in this commentary points to a less traveled research path that might lead to an alternative pedagogical scenario for STEM education research.

\section{Acknowledgements}

The author would like to express deep gratitude to the teachers of Maryknoll Father's School, Hong Kong SAR, for sharing their school practices.

\section{Author's contributions}

This commentary is sole-authored. The author read and approved the final manuscript.

\section{Funding}

The author declares that there is no funding for this research.

\section{Availability of data and materials}

Data sharing is not applicable to this commentary as no empirical data were generated.

\section{Competing interests}

The author declares that he has no competing interests.

Received: 11 October 2019 Accepted: 20 March 2020

Published online: 20 April 2020

\section{References}

Akkerman, S. F., \& Bakker, A. (2011). Boundary crossing and boundary objects. Review of Educational Research, 81(2), 132-169.

Artigue, M., \& Baptist, P. (2012). Inquiry in mathematics education. In S. B. Carulla (Ed.), Resources for Implementing Inquiry in Science and Mathematics at School The Fibonacci Project. Retrieved from http://www.fibonacci-project.eu/.
Burrows, V., Oehrtman, M., \& Lawson, A. (2006). Development of an integrated learning framework for STEM learning. In ASEE Annual Conference and Exposition, Conference Proceedings (pp. 2006-1074).

Bybee, R. W., Taylor, J. A., Gardner, A., Van Scotter, P., Powell, J. C., Westbrook, A., \& Landes, N. (2006). The BSCS $5 E$ instructional model: Origin and effectiveness. A report prepared for the Office of Science Education National Institutes of Health. U.S.A. Colorado Spring: BSCS.

Corlu, M. S., Capraro, R. M., \& Capraro, M. M. (2014). Introducing STEM education: Implications for educating our teachers for the age of innovation. Education and Science, 39(171), 74-85.

Dillion, P. (2008). A pedagogy of connection and boundary crossings: Methodological and epistemological transactions in working across and between disciplines. Innovations in Education and Teaching International, 45(3), 255-262.

Education Bureau of Government of HKSAR. (2016). Report on promotion of STEM education: Unleashing potential in innovation. Retrieved from https:// www.edb.gov.hk/attachment/en/curriculum-development/renewal/STEM\%2 OEducation\%20Report_Eng.pdf

Engeström, Y., Engeström, R., \& Kärkkäinen, M. (1995). Polycontextuality and boundary crossing in expert cognition: Learning and problem solving in complex work activities. Learning and Instruction, 5, 319-336.

English, L. (2016). STEM education: Perspectives on integration. International Journal of STEM Education, 3, 3. https://doi.org/10.1186/s40594-016-0036-1.

Hallström, J., \& Schönborn, K. J. (2019). Models and modelling for authentic STEM education: Reinforcing the argument. International Journal of STEM Education, 6(22). https://doi.org/10.1186/s40594-019-0178-z.

Kelly, T. R., \& Knowles, J. G. (2016). A conceptual framework for integrated STEM education. International Journal of STEM Education, 3(11). https://doi.org/10. 1186/s40594-016-0046-z.

Lava, J., \& Wenger, E. (1991). Situated learning: Legitimate peripheral participation. Cambridge: Cambridge University Press.

Leung, A. (2018). Pólya's problem solving cycle as a boundary object for the STEM disciplines' inquiry processes. In Post-Conference Proceedings of the Integrated Education for the Real World 5th International STEM in Education Conference (pp. 205-212). Brisbane: Queensland University of Technology https://stem-in-ed2018.com.au/wp-content/uploads/2019/02/5thInternational-STEM-in-Education-Post-Conference-Proceedings-2018_1502.pdf.

Leung, A. (2019). Exploring STEM pedagogy in the mathematics classroom: A tool-based experiment lesson on estimation. International Journal of Science and Mathematics Education, 17(7), 1339-1358.

Li, Y., Schoenfeld, A. H., disessa, A. A., Craesser, A. C., Benson, L. C., English, L. D., \& Duschl, R. A. (2019). On thinking and STEM education. Journal for STEM Education Research, 2(1). https://doi.org/10.1007/s41979-019-00014-x.

Pólya, G. (1945). How to solve it. Princeton: Princeton University Press.

Priemer, B., Eilerts, K., Filler, A., Pinkwart, N., RöskenWinter, B., Tiemann, B., \& Upmeier Zu Belzen, A. (2019). A framework to foster problem solving in STEM and computing education. Research in Science \& Technological Education. https://doi.org/10.1080/02635143.2019.1600490.

Sanders, M. (2009). STEM, STEM education, STEM mania. The Technology Teacher, 68(4), 20-26.

Star, L. S., \& Griesemer, J. R. (1989). Institutional ecology, 'translations' and boundary objects: Amateurs and professional in Berkeley's Museum of Vertebrate Zoology, 1907-30. Social Studies of Science, 19(3), 387-420.

Tang, K. S., \& Williams, P. J. (2019). STEM literacy or literacies? Examining the empirical basis of these constructs. Review of Education, 7(3), 675-697.

Vasquez, J., Sneider, C., \& Comer, M. (2013). STEM lesson essentiall, grades 3-8: Integrating science, technology, engineering, and mathematics. Portsmouth: Heinemann.

Wenger, E. (1998). Communities of practice, learning, meaning and identity. Cambridge: Cambridge University Press.

Wenger, E. (2015). Communities of practice: A brief introduction. Retrieved from http://wenger-trayner.com/introduction-to-communities-of-practice/ on October 24, 2018.

Wenger, E., McDermott, R., \& Snyder, W. M. (2002). Cultivating communities of practice. Cambridge: Harvard Business School Press.

\section{Publisher's Note}

Springer Nature remains neutral with regard to jurisdictional claims in published maps and institutional affiliations. 